\title{
The SARS COV-2 - The Great Imitator: Neuropsychiatric Masquerades: a systematic review and case report
}

\author{
Karishma Rupani ${ }^{1}$, Shilpa Adarkar ${ }^{2}$ \\ ${ }^{1}$ Assistant Professor, \\ ${ }^{2}$ Associate Professor, \\ Department of Psychiatry, Seth GS Medical College and KEM Hospital, Mumbai. \\ Corresponding author: Karishma Rupani \\ Email - k.i.rupani@gmail.com
}

\begin{abstract}
The COVID-19 pandemic has affected people worldwide and across all nations. The present review aims at presenting the various neuropsychiatric manifestations of COVID with an aim of describing how these manifestations may be missed and how neuropsychiatric manifestations are embedded in the presenting features viral infections like COVID. The fear related to contracting and spreading SARS CoV-2 has not only expressed itself in the rising number of cases of diagnosable psychiatric disorders, but has also resulted in an increasing number of suicides. Working in a tertiary general hospital, we have seen in liaison practice, a relatively increased number of cases of late onset and first episode psychosis, unexplained agitation, features of anxiety, depression, suicide attempts and completed suicides without any apparent precipitating stressor and of a severity rather disproportionate to the environmental or social stressors. Viral infections and viral theories of psychiatric disorders like schizophrenia abound psychiatric literature. The present review was conceived to present the various neuropsychiatric manifestations and masks that may be seen in COVID cases.
\end{abstract}

Key words: neuropsychiatric, COVID-19, psychiatric disorders, depression, suicide.

(Paper received $-22^{\text {nd }}$ August 2020, Peer review completed $-10^{\text {th }}$ September 2020)

(Accepted $-11^{\text {th }}$ September 2020)

\section{INTRODUCTION}

The COVID-19 pandemic has gripped us all, from the loss of lives to the fear of losing life, and has been unprecedented at that. Uncertainty, loss of jobs, disruption of daily routine and social isolation are some of the reasons for a rapid rise in the cases of anxiety and depression, so much so that the World Health Organization (WHO) has issued public interest guidelines to address psychological issues [1]. Also the heightened fear related to contracting and spreading SARS CoV-2 has not only expressed itself in the rising number of cases of diagnosable psychiatric disorders [2], but has also resulted in an increasing number of suicides [3].

However, not all 'psychiatric symptoms' can be attributed to problems with adjusting to the 'new normal'; especially, when, in liaison practice we see a relatively increasing number of cases of late onset, first episode psychosis, unexplained agitation, features of anxiety, depression, suicide attempts and completed suicides without any apparent precipitating stressor and of a severity rather disproportionate to the environmental or social stressors.

We are all aware of the 'viral hypothesis of Schizophrenia [4] and, an entity called Encephalitis Lethargica (EL) wherein hypersomnolence, psychosis, catatonia and Parkinsonism were attributed to an inflammatory disorder of the CNS as a result of the 'Spanish influenza' pandemic [5]. 
If we re-examine studies of respiratory viral pandemics in the $18^{\text {th }}$ and $19^{\text {th }}$ century, we see that apart from respiratory symptoms, there was an increase in the incidence of various syndromes affecting the cognitive, affective, behavioral, and perceptual domains, all of which could not be explained by the psychosocial model of causation alone, these features included insomnia, anxiety, depression, mania, psychosis, and suicide [4]. Neuropsychiatric manifestations of the SARS CoV 1 (Severe Acute Respiratory Syndrome Coronavirus 1) in 2003 and the MERS CoV (Middle East Respiratory Sydrome Coronavirus) epidemic in 2009 revealed that during the acute illness, common symptoms apart from those which were respiratory in nature; included confusion, depressed mood, anxiety, impaired memory and insomnia [6].

Taking from the current SARS-CoV-2 pandemic, a study showed that about $36 \%$ of SARS CoV-2 positive patients presented with neuropsychiatric symptoms, instead of the usual presenting symptoms of fever, cough and breathlessness [7].

Therefore, this should put to question our understanding of "asymptomatic carriers" of infection and will hopefully have a bearing on the indications for COVID 19 testing, which will have a bearing on our isolation and treatment strategies, in the wake of a second wave. Hence the current review was carried out, to understand the various manifestations (masks) that the SARS CoV2 presents with.

\section{SEARCH STRATEGY}

We did a systematic search for neurological and psychiatric symptoms associated with the SARS-CoV-2, using databases such as PubMed, Google Scholar, Science Direct and Medscape. The following keywords were used in the search using the MeSH terminology- "Psychiatry" "COVID 19"; "SARS Pathophysiology" "pandemic", "MERS" "Neurology"; "Psychosis"; "first episode psychosis", "catatonia" "immunology"; "neuroimunology" "inflammation"; "immunomodulatory drugs". We were able to find 5012 articles.

We excluded the articles related to psychiatric disorders in those who never tested positive for CoV-2 and excluded substance induced disorders, duplicates, cross references.

\section{NEUROPSYCHIATRIC MANIFESTATIONS}

We know that reports from the 18th and 19th century suggested that influenza pandemics apart from the respiratory symptoms, showed an increase in the incidence of insomnia, anxiety, depression, mania, psychosis, suicide and delirium and an exposure to viral infections in adults, in utero and during childhood development, have each been associated with increased risk of developing schizophrenia; what we call the 'viral hypothesis of Schizophrenia' as of today [4] and hypersomnolence, psychosis, catatonia, and Parkinsonism, which were attributed to an inflammatory disorder of the CNS caused by the "Spanish" influenza pandemic, an entity called Encephalitis Lethargica (EL) [5].

A meta-analysis of the neuropsychiatric manifestations of SARS epidemic in 2003 (SARS CoV-1) and MERS CoV in 2009 revealed that during the acute illness, common presenting symptoms included confusion (27.9\%), depressed mood (32.6\%), anxiety (35.7\%), impaired memory (34.1\%) and insomnia $41.9 \%$ [6]. In the post-illness stage, depressed mood (10.5\%), insomnia (12.1\%), anxiety $(12.3 \%)$, irritability $(12.8 \%)$, memory impairment $18.9 \%$, fatigue $19.3 \%$, traumatic memories $(30.4 \%)$ and sleep disorders $(100 \%)$ were frequently reported [7] and neurological conditions such as polyneuropathy, encephalitis, and aortic ischemic stroke were seen [8]. This can be explained as both SARS-COV1 and MERS-COV are neurotropic and neuro-invasive [9], and an autopsy of the deceased demonstrated signs of cerebral edema and meningeal vasodilation. This was seen along with the infiltration of monocytes and lymphocytes in the vessel wall, ischemic changes of neurons, demyelination of nerve fibers, and the detection of SARS-CoV virus particles (by genome sequencing) in the brain [10].

In a study done, $70.8 \%$ had Psychiatric symptoms as the only presenting complaints [11], while another study reported insomnia, impaired memory and persecutory ideas [12]. Chronic fatigue was associated with active psychiatric illness in a study done [13]. Various neuropsychiatric manifestations have been outlined in Table 1. 
Table 1: Neuropsychiatric manifestations of SARS COV

\begin{tabular}{|c|c|c|c|}
\hline Study & $\begin{array}{l}\text { Sample size } \\
\text { Type of study }\end{array}$ & Presenting complaints & Highlights \\
\hline $\begin{array}{l}\text { SARS CoV-1 } \\
\text { (Rogers et.al. 2020) } \\
\text { [6] }\end{array}$ & $\begin{array}{l}3559 \\
\text { Meta-analysis }\end{array}$ & $\begin{array}{l}\text { Meta-analysis of the } \\
\text { Neuropsychiatric manifestations of } \\
\text { SARS epidemic in } 2003 \text { (SARS } \\
\text { CoV-1) and MERS CoV in } 2009 \\
\text { IN THE ACUTE PHASE } \\
\text { Common symptoms included } \\
\text { Confusion (27.9\%), } \\
\text { Depressed mood (32.6\%), } \\
\text { Anxiety (35.7\%), } \\
\text { Impaired memory (34.1\%) } \\
\text { Insomnia (41.9\%). } \\
\text { IN THE POST-ILLNESS STAGE } \\
\text { Sleep disorder (100\%) } \\
\text { Traumatic memories (30.4\%) } \\
\text { Fatigue (19.3\%) } \\
\text { Depressed mood (10.5\%) } \\
\text { Anxiety (12.3\%) } \\
\text { Irritability (12.8\%) } \\
\text { Memory impairment (18.9\%) }\end{array}$ & $\begin{array}{l}\text { The SARS CoV-2 and MERS both can } \\
\text { present with neuropsychiatric symptoms } \\
\text { a presenting complaint. Hence to } \\
\text { decrease transmission, detect and isolate. } \\
\text { Similarly, we also ought to be aware that } \\
\text { in the long term we may come across cases } \\
\text { in psychiatry that are post infection } \\
\text { manifestations. }\end{array}$ \\
\hline MERS [11] & $\begin{array}{l}\mathrm{N}=24 \\
\text { Acute phase }\end{array}$ & $\begin{array}{l}70.8 \% \text { had Psychiatric symptoms as } \\
\text { the only presenting complaints } \\
\text { Anxiety/ tension }[37.5 \%], \\
\text { Insomnia }[29.2 \%] \\
\text { Depressed mood }[20.8 \%] \\
\text { Disorientation }[8.3 \%], \\
\text { Impaired memory }[8.3 \%], \\
\text { Auditory hallucinations }[8.3 \%] \\
\text { Aggressive outbursts }[8.3 \%]) \\
\text { Mild neurocognitive disorder } \\
\text { [4.2\%] }\end{array}$ & $\begin{array}{l}\text { That not all patients infected with the } \\
\text { MERS virus presented with complaints } \\
\text { of fever, cough and breathlessness. } \\
\text { High of index of suspicion required as } \\
\text { cases presenting without respiratory } \\
\text { symptoms harbor the virus ad spread } \\
\text { infection. }\end{array}$ \\
\hline Sheng et al. [12] & $\begin{array}{l}\mathrm{n}=102 \\
\text { Observational } \\
\text { analysis }\end{array}$ & $\begin{array}{l}\text { MOOD AND ANXIETY } \\
\text { Insomnia (46.1\%) } \\
\text { Low mood }(36.3 \%) \\
\text { Tension }(36.3 \%), \\
\text { Fear and panic }(26.5 \%) \\
\text { Crying spell }(23.5 \%), \\
\text { Irritability/yelling (4.9\%), } \\
\text { COGNITIVE DYSFUNCTION } \\
\text { Impaired memory (41.2\%) } \\
\text { Poor concentration }(38.2 \%) \\
\text { Disoriented in time }(33.3 \%) \\
\text { and place (3.9\%) } \\
\text { PSYCHOTIC FEATURES } \\
\text { Persecutory ideas }(3.9 \%), \\
\text { Auditory hallucination }(3.9 \%), \\
\text { Visual hallucination }(2.0 \%) \text { and } \\
\text { Suicidal ideation }(2.0 \%)\end{array}$ & $\begin{array}{l}\text { Severity for infection and corticosteroids } \\
\text { therapy were associated with symptoms } \\
\text { of anxiety, depression, psychosis and } \\
\text { behavioral problems. Health care work } \\
\text { was associated with more cognitive } \\
\text { problem. }\end{array}$ \\
\hline Lam et al [13] & $\begin{array}{l}\mathrm{n}=181 \\
31-51 \text { months }\end{array}$ & $\begin{array}{l}\text { The most common diagnoses were } \\
\text { PTSD }(23.2 \%) \text {, depression }(16.6 \%) \text {, } \\
\text { somatoform pain disorder }(15.5 \%) \text {, } \\
\text { panic disorder }(13.8 \%) \text { OCD }(6.6 \%)\end{array}$ & $\begin{array}{l}\text { Chronic fatigue was associated with } \\
\text { active psychiatric illness. }\end{array}$ \\
\hline
\end{tabular}


The SARS CoV-2 virus (belonging to the $\beta$-coronavirus family) is taxonomically similar to coronaviruses such as SARS-COV-1 and MERS-COV both of which caused neuropsychiatric syndromes affecting cognitive, affective, behavioral, and perceptual domains and both of which are neurotropic and neuroinvasive [14].

\section{ETIOLOGICAL THEORIES OF THE NEUROPSYCHIATRIC MANIFESTATIONS OF SARS COV-2}

Beginning with the entry of the virus in any cell, the ACE-2 receptor acts as the entry port for the virus. ACE-2 receptors express 2 cells (goblet and ciliated) that have been identified as likely infection points for the SARS-CoV-2. Once attached, the virus employs the host cell enzyme, Transmembrane Serine Protease 2 (TMPRSS2) to expose fusion peptides, that fuse the viral membrane with the host cell, allowing the virus to enter the cell [15].

\section{How does the virus gain access to the neuronal cells}

There are two postulated pathways one direct and the other indirect pathway

1. Direct pathway involves neuronal transport of the virus

How does this happen

- The pathways for the SARS CoV-2 to gain access to our nervous system (central and peripheral) is through retrograde axonal transport via the olfactory pathway, The Gut - Brain axis and the respiratory system. Let us examine each.

\section{Olfactory pathway}

Retrograde neuronal transport via the olfactory pathway occurs because the olfactory cilia have ACE2 receptors, after binding to the receptors, retrograde transport occurs through the cribriform plate onto the olfactory bulb (anosmia) and basal part of the forebrain, within about 7 days of infection thereby causing neuronal infection and inflammation [16].

\section{Gut-Brain Axis}

The very first symptom of COV2 infection was of gastrointestinal origin with complaint of diarrhea, vomiting; without respiratory symptoms and it was found on follow up testing that, viral shedding in feces can occur up to 5 weeks post-infection, until which the patient could potentially infect others [17].

The gut is postulated as a key entry point due to the following factors: The expression of ACE-2 receptors is higher in the enterocytes than the lungs, thus the SARS-CoV-2 virus can directly infect and replicate in the intestinal cells. However, the enterocytes are connected to the enteric nervous stem and thereby provide a source of entry to the brain (by retrograde axonal transport) and cause inflammation, as a result of which, those with coexisting GI and respiratory symptoms, have worse clinical outcomes, with need for assisted ventilation. Another route is through the Antigen Presenting Cells of the Gut Associated Lymphoid Tissue (GALT) which breach the blood brain barrier causing neuronal infection [18].

\section{Respiratory network}

The virus may also enter via retrograde neuronal transport via axons from the peripheral nerves of the respiratory network into the medulla oblongata, where respiratory rhythm is generated and regulated [19]. Therefore, despite low levels of oxygen saturation, patients don't complain of breathlessness, which goes by the name of 'happy hypoxia'. So far we have seen how via axonal transport the virus gets access to the brain and causes infection and inflammation. This is the basic premise of the following clinical presentations of COV-2 infection. 


\section{CLINICAL PRESENTATION}

\section{Delirium and psychotic disorders}

In a study done by Helms [20] agitation was a presenting feature in 40 out of 58 patients. Out of these 40 patients, $26(65 \%)$ were delirious. The rest (35\%) presented with agitation, (without confusion, delirium or psychotic features), that is they had unexplained agitation as the initial presenting symptom. Thus, timely recognition and initiation of treatment could prove to be helpful. During the COVID19 pandemic, it has been found that between $0.9 \%$ and $4 \%$ of people exposed to the virus (tested positive on nasopharyngeal swab test) have developed psychosis or psychotic symptoms (hallucinations and/or delusions) [21].

Authors have reported an increase in the incidence of first-episode psychosis with a shift towards late age of onset in those who were tested for and were found to be positive for SARS CoV 2 virus, on throat swab samples. Thus, a high index of suspicion is warranted for early testing, and isolation, thereby decreasing the spread of infection [22].

\section{Headache}

As psychiatrists we have not been trained to think of causes other than migraine, tension type headache or chronic daily headache, when treating patients with headache as a presenting complaint. However, bear in mind that a number of studies have reported headache as an initial symptom in those who were found to be covid 19 positive. The incidence of headache as a sole presenting feature in COV 2 positive patients has been found, with studies showing rates from $8-70 \%$ [23] and a meta-analysis showing a prevalence of headache at $12 \%$ [24], which were later followed by the typical respiratory complaints around 5 to 7 days later, providing a window of opportunity to diagnose and treat, thereby decreasing the chances of spread.

\section{Cerebrovascular events [25]}

A case series of 221 patients with COVID-19 showed 11 (5\%) developed acute ischemic stroke, $1(0 \cdot 5 \%)$ cerebral venous sinus thrombosis (CVST), and $1(0 \cdot 5 \%)$ cerebral hemorrhage [25-26]. Hypercoagulability is associated with stroke in younger individuals.

Peripheral neuropathy, anosmia, dysguesia, myopathy and Guillain-Barre syndrome are rare nerve diseases linked to demyelination [7].

\section{Neurodegenerative Disorders}

Bianchetti and others [27] stated that given that neural and immune cells can serve as reservoirs of latent $\mathrm{CoV}$, it is plausible that this could contribute to delayed neurodegenerative processes,

\section{Gastrointestinal Disorders}

In a study done by Xin and others [18], 11.4\% presented with at least one GI symptom (nausea, vomiting or diarrhea), of cov2 positive patients, $22.97 \%$ had severe GI symptoms and $31.08 \%$ had family clustering, therefore attention to patients with GI symptoms is of importance to prevent spread of infection.

\section{FIRST EPISODE PSYCHOSIS}

In a study by Brown et al. [21] incident cases of psychosis in people infected with COV 2 virus was in the range of $0.9 \%$ to $4 \%$. Hu and others reported an increase in the incidence of first-episode psychosis with a shift towards late age onset in those who were tested for and were found to be COV 2 positive on throat swab samples [28]. Thus, vigilance for early testing/isolation in those with first episode, sudden onset of psychotic features is warranted.

Now, coming to the postulated Indirect Mechanisms of neuronal Involvement (That is without any direct access of the virus to the brain or neuronal cells). This involves inflammatory chemicals affecting the brain, a study of Psycho-Neuro-Immunology. 


\section{BASIC PREMISE OF PSYCHO-NEURO-IMUNOLOGY}

\section{Cytokine dysregulation}

Infection with SARS-CoV-2, leads to the release of large amounts of pro-inflammatory cytokines (IFN $\alpha$, IFN $\gamma$, IL-1 $\beta$, IL-6, IL-12, TNF $\alpha$, TGF $\beta$ ) and chemokines (CXCL10, CXCL8, CXCL9, both of which have powerful chemo-attractant activity leading to immune cell recruitment during inflammation [30].

\section{Cytokine Storm}

Thus, uncontrolled and over-production of soluble markers of inflammation which, in turn, sustain an aberrant systemic inflammatory response, is what we call "CYTOKINE STORM SYNDROME", which is characterized by a fulminant and fatal hyper-cytokinemia associated with multi-organ failure and mortality. Pro-inflammatory cytokines (e.g., IL-6 and TNF- $\alpha$ ) are significantly higher among deceased COVID-19 patients, which has previously been linked to cytokine storm syndrome-related encephalitis [30].

\section{Neuro-inflammation and neuropsychiatric manifestations of COV 2 infection}

Cytokines released through peripheral inflammation may increase the permeability of the BBB providing a pathway for the virus to enter the brain. Once in the CNS, it activates a cascade of neuro-inflammation and neuro-degeneration through the release of TNF, cytokines, ROS and other inflammatory mediators [31]. Thus, it has been observed that the severe clinical manifestations of the disease could not be ascribed only to the viral activity per se, but that an immune-mediated mechanism played an important role in causing neuronal damage, driving the clinical progression of neuropsychiatric manifestations of COV 2 infection [30]. In this context, Interleukin-6 (IL-6) and C Reactive Protein (CRP) deserve a more extensive discussion in view of their involvement in the coronavirus-induced cytokine storm as acute phase biomarkers. High serum levels of IL-6 and is now a widely proposed and used predictor of disease severity [30].

\section{Post-infectious autoimmunity}

Viral infections have been suggested to induce auto-reactive processes that can potentiate the development of an autoimmune response in susceptible individuals. In fact, the literature has already described cases of autoimmunity following SARS-CoV-1 and MERS-CoV infection [32].

The SARS-CoV-2 epitopes bear a structural resemblance to several human proteins. Molecular mimicry between the virus epitope and myelin basic protein leads to an immune attack against the host cells, causing demyelination, skeletal muscle breakdown, hypercoagulability and acute renal injury. This is one of the many factors contributing to critical illness and mortality in COVID-19 via autoimmunity [33].

\section{ETIOPATHOGENESIS OF THE MANIFESTATIONS OF PSYCHIATRIC SYMPTOMS IN COV 2 POSITIVE PATIENTS}

In retrospect, we have seen increased levels of various cytokines in several psychiatric disorders. Soluble cytokines that reach the brain can influence synthesis, release and reuptake of several neurotransmitters, including monoamines, such as dopamine, norepinephrine, and serotonin. Also, changes in the metabolism of neurotransmitters that occur as a result of inflammatory molecules are involved in the pathophysiology of various psychiatric disorders, such as depression, anxiety, PTSD, and obsessive-compulsive disorder, not just that but soluble markers such as IL-6 ad CRP, to name a few also cause dysfunction of the HypothalamoPitiutary-Adrenal (HPA) Axis and a consequent increase in serum cortisol levels, as another causative factor for psychiatric symptoms [31].

\section{Psychotic features}

In a noteworthy case report, psychotic symptoms characterized by psychomotor agitation, anxiety, thought disorganization, persecutory delusions and auditory hallucinations, followed by dysphagia, dysarthria and seizures in a SARS COV-2 positive patient, for which the patient was given antiviral medication (Remdesivir, HCQ) with little improvement, the patient's serological testing showed an increased IL-6 and CSF anti-NMDA receptor antibodies. A diagnosis of anti-NMDAR encephalitis was made. High doses of dexamethasone and intravenous immunoglobulin (IVIG) were administered with improvement [34]. 


\section{ANXIETY AND DEPRESSIVE FEATURES}

Studies showed that Inflammation was associated with a range of depression symptoms, particularly with tiredness, lack of energy, sleep problems, and changes in appetite. These symptoms characterize what we call 'sickness behaviors'. Inflammation was also associated with the cognitive and emotional symptoms of depression (eg. anhedonia, depressed mood, feelings of self-worth, lack of concentration, and suicidal ideation).

\section{LABORATORY BIOMARKERS}

In a study done by Dantz et al, Laboratory findings showed elevated levels of inflammatory markers, such as C-reactive protein in people with depression. It was suggested that this association may, in fact, be symptom-specific, in that higher levels of inflammation are particularly likely to underlie symptoms that characterize sickness behavior, including fatigue, reduced appetite, withdrawal, and inhibited motivation [36].

\section{Trait versus State Markers:}

- Evidence suggests that IL-6 may be a state marker of schizophrenia, as it is elevated only in currently symptomatic patients, but not in stable outpatients

- Some studies have found IL-6 to be correlated with duration of illness or

- Being a potential biomarker for early psychotic symptoms [37].

- In contrast, other inflammatory markers, including TNF- $\alpha$ and interferon (IFN)- $\gamma$, been suggested as possible trait markers [38].

\section{CLINICAL APPLICATION OF BIOMARKERS}

As an extended application, cytokines could help stratifying population samples for clinical trials testing new therapeutic agents. In particular, it has recently been reported that baseline IL-6 levels may predict treatment response to ketamine in treatment-resistant depressed patients, with higher IL-6 levels amongst responders [39].

\section{Reactive Protein (CRP)}

C-reactive protein has been associated with all the specific depression symptoms. Independent associations were apparent specially with sleep problems, and changes in appetite. The independent association with anhedonia was close to statistical significance. With $\mathrm{C}$ reactive protein, a dose-response pattern was observed for sleeping problems, tiredness or lack of energy changes in appetite [40].

\section{Case 1}

Male, 56 years old, hypertensive, came with complaints of decreased interaction with family members, lethargy, decreased interest in activities, decreased appetite, episodes of panic attacks and decreased sleep and headache since 15 days. He had no past nor a family history of psychiatric illness. There was no history of fever, cough, breathlessness or any high risk contact. His blood pressure was 146/90, while on $5 \mathrm{mg}$ of Amlodipine. There was no history suggestive of delirium, no agitation, no history suggestive of psychosis or any other systemic abnormalities on examination. However, considering the age, no past or family history, no substance use, without any precipitating factors or stressor, and a rather sub-acute onset, routine investigations were done. The reports showed a raised WBC count of 8000 and an ESR of 20 with normal renal and liver function test reports. Serum CRP was done which was $14 \mathrm{mg} / \mathrm{L}$. The patient however did not fulfil criteria for a COV 2 nasopharyngeal swab test. An HRCT of the chest was done which showed peripheral infiltrates with a ground glass appearance in both the lungs. Antigen testing was done which turned out to be positive for cov 2 and the patients was admitted. Only 6 days later, did the patient complain of breathlessness and cough. Thereafter the patient was lost to follow up. 


\section{Blood picture of COV 2 positive patients with CNS symptoms}

Immunologic test results from COVID-19 patients show that CNS symptoms such as headache, dizziness, and ataxia are linked to significantly lower blood lymphocyte counts, platelet counts, and higher blood urea nitrogen levels compared to those without CNS symptoms. Lymphopenia has been suggested to be indicative of immunosuppression in patients with CNS symptoms. Patients with CNS symptoms had lower lymphocyte levels, platelet counts and blood urea nitrogen compared with those without CNS symptoms. Patients with muscle injury had significantly higher levels of Creatine Kinase had higher neutrophil counts, Lower lymphocyte counts, higher C-reactive protein levels, and higher D-dimer levels [7]. The abnormalities were manifestations of increased inflammatory response and hypercoagulability.

\section{Psychotropic drugs with immuno-modulatory effects}

The in vitro literature on antidepressants shows that some antidepressants, such as clomipramine and fluoxetine, more consistently decrease proinflammatory cytokines, interleukin-6 (IL-6), interferon (IFN)- $\gamma$, Tumor Necrosis Factor $\alpha$ (TNF- $\alpha$ ), whilst others like mirtazapine and venlafaxine [42] tend to increase cytokine levels with patients complaining of pain and soreness of muscles. However, caution is warranted as fluoxetine inhibits liver enzymes and clomipramine lowers the seizure threshold. Haloperidol inhibited Nuclear Factor-kB activation, and thereby suppressed expression of CD80, as well as secretion of IL-1b, IL6, and IL-12 p40. CD80 and IL-6 levels were similarly attenuated by a D2-like receptor antagonist, but not by a D1-like receptor antagonist [43], however an ECG should be done prior to initiation and QTc interval should be monitored as haloperidol has the propensity to prolong the QTc interval.

\section{Vigilance for side effects of psychotropic drugs in routine use}

When using any SSRI, weigh risks and benefits in patients with recent bleeding or high risk for bleeding (e.g., thrombocytopenia, concurrent anticoagulation therapy (LMW-Heparin) which is used in patients suffering from moderate to severe symptoms of infection with SARS COV-2.

Our patients on clozapine and carbamazepine, to name a few, are monitored for blood dyscrasias. However, there is a class effect FDA warning on all first and second generations antipsychotics for the potential association with leukopenia, neutropenia, and agranulocytosis. Carbamazepine is more likely to be associated with an early transient leukopenia and has also been associated with agranulocytosis and aplastic anemia [44]. It has been suggested that clozapine, specifically is associated with a higher risk of pneumonia and its complications, reasons for this include aspiration, sialorrhea, sedation, and poorly understood effects on the immune system [45]. Challenges faced in practicing Liaison psychiatry is that drugs used rather sparingly, earlier like Chloro-quine and hydroxychloroquine, tocilizumab, Remdesivir, atazanavir, lopinavir/ritonavir, favipiravir and Azithromycin amongst antibiotics, are now used almost empirically in COV 2 positive patients and some also using it prophylactically. Hydroxychloroquine (HCQ) can cause anxiety and, less frequently, psychosis. The list doesn't end here, Corticosteroids, given as a bolus or rather large oral doses or can cause manic and psychotic symptoms [46].

\section{Drug interactions}

HCQ and can interact with antipsychotics, increasing the levels of phenothiazines [46]. Atazanavir and liponavir/ritonavir can substantially increase the levels of quetiapine, lurasidone, ziprasidone, and pimozide, as well as benzodiazepines, such as midazolam and triazolam [47]. Carbamazepine, meanwhile, reduces levels of atazanavir, remdesivir, chloroquine, and hydroxychloroquine. Disulfiram and nalmefene should be discontinued in patients with alcohol addiction. In patients treated with clozapine, SARS CoV2infection may lower the white blood cell count [48].

\section{CONCLUSIONS}

SARS CoV 2 is a respiratory virus and may damage the CNS as a result of direct neuroinvasion by retrograde axonal transport, which directly causes damage to neuronal cells or by the effect of inflammatory markers on neuronal cells, neurotransmitters and the HPA axis or as a result of misdirected host immune response 
that could be associated with autoimmunity. This phenomenon could also initiate later, in the post-acute phase of the illness and therefore the importance of follow up cannot be over emphasized. This review highlights the diverse presentations of covid 19, clinicians should be alert of the propensity of SARS COV-2 to mimic non respiratory systemic manifestations. The onset of respiratory symptoms sometimes starts after 5 to 7 days after the presenting complaint. Thus, testing strategies can be modified so that detection and containment strategies can be implemented before infection spreads. Serum biomarkers like CRP and IL-6 are simple non-invasive tests, used by many as a prequel to HRCT or chest radiography in those with sudden neuropsychiatric symptoms. These findings should direct future research to establish the role of early sensitive and specific markers of SARS CoV 2 infection without there being respiratory symptoms because SARS COV 2 is a great imitator.

\section{REFERENCES}

1. WHO. (2020). Mental health and psychosocial considerations during the COVID-19 outbreak [Ebook]. Retrieved from https://www.who.int/docs/default-source/coronaviruse/mental-health-considerations.pdf.

2. Wang C, Pan R, Wan X, Tan Y, Xu L, Ho C, Ho R. Immediate psychological responses and associated factors during the initial stage of the 2019 Coronavirus Disease (COVID-19) epidemic among the general population in China. Int J Environ Res Pub Health. 2020;17(5):1729.

3. Goyal K, Chauhan P, Chhikara K, Gupta P, Singh M. Fear of COVID 2019: First suicidal case in India! Asian J Psychiatry 2020;49:101989.

4. Menninger KA. Influenza and schizophrenia. Am J Psychiatry 1926;82:469-529.

5. Von Economo C. Encephalitis lethargica, its sequelae and treatment. JAMA 1932;98:255.

6. Rogers JP, Chesney E, Oliver D, Pollak TA, McGuire P, Fusar-Poli P, Zandi MS, Lewis G, David AS. Psychiatric and neuropsychiatric presentations associated with severe coronavirus infections: a systematic review and meta-analysis with comparison to the COVID-19 pandemic. Lancet Psychiatry 2020;6(7):611-27.

7. Mao L, Jin H, Wang M. Neurologic Manifestations of Hospitalized Patients With Coronavirus Disease 2019 in Wuhan, China. JAMA Neurol 2020;77(6):683-90.

8. Tsai LK, Hsieh ST, Chang YC. Neurological manifestations in severe acute respiratory syndrome. Acta Neurol Taiwan 2005;14(3):113-9.

9. Arciniegas DB, Anderson CA. Viral encephalitis: Neuropsychiatric and neurobehavioral aspects. Curr Psychiatry Rep 2004;6:372-9.

10. Gu J, Gong E, Zhang B, Zheng J, Gao Z, Zhong Y. Multiple organ infection and the pathogenesis of SARS. J Exp Med 2005;202(3):415-24.

11. Kim JE, Heo JH, Kim HO, Song SH, Park SS, Park TH. Neurological Complications during Treatment of Middle East Respiratory Syndrome. J Clin Neurol 2017;13(3):227-33.

12. B Sheng, SKW Cheng, KK Lau, HL Li, ELY Chan. The effects of disease severity, use of corticosteroids and social factors on neuropsychiatric complaints in severe acute respiratory syndrome (SARS) patients at acute and convalescent phases Eur Psychiatry 2005;20:236-42.

13. Lam MH. Mental morbidities and chronic fatigue in severe acute respiratory syndrome survivors. Arch Intern Med 2009;169:2142-8.

14. Wu Y, Xu X, Chen Z, Duan J, Hashimoto K, Yang L, Liu C, Yang C. Nervous system involvement after infection with COVID-19 and other coronaviruses. Brain Behav Immun 2020;87:18-22.

15. Wrapp D, Wang N, Corbett KS, et al. Cryo-EM structure of the 2019-nCoV spike in the prefusion conformation. Science 2020;367(6483):1260-3.

16. Li YC, Bai WZ, Hashikawa T. The neuroinvasive potential of SARS-CoV2 may play a role in the respiratory failure of COVID-19 patients. J Med Virol 2020;92(6):552-5.

17. Wu Y, Guo C, Tang L, Hong Z, Zhou J, Dong X, Yin H, Xiao Q, Tang Y, Qu X, Kuang L. Prolonged presence of SARS-CoV-2 viral RNA in faecal samples. Lancet Gastroenterol Hepatol 2020;5(5):434-5.

18. Jin X, Lian JS, Hu JH, Gao J, Zheng L, Zhang YM, Hao SR, Jia HY, Cai H, Zhang XL, Yu GD. Epidemiological, clinical and virological characteristics of 74 cases of coronavirus-infected disease 2019 (COVID-19) with gastrointestinal symptoms. Gut 2020;69(6):1002-9.

19. Ng SC, Tilg H. COVID-19 and the gastrointestinal tract: more than meets the eye. Gut 2020;69(6):973-4.

20. Helms J, Kremer S, Merdji H, Clere-Jehl R, Schenck M, Kummerlen C. Neurologic features in severe SARSCoV-2 infection. N Engl J Med 2020;382(23):2268-70.

21. Brown E, Gray R, Monaco SL, O'Donoghue B, Nelson B, Thompson A, Francey S, McGorry P. The potential impact of COVID-19 on psychosis: A rapid review of contemporary epidemic and pandemic research. Schizophr Res 2020:May 6 (ahead of print).

22. Guan WJ, Liang WH, Zhao Y, Liang HR, Chen ZS, Li YM, Liu XQ, Chen RC, Tang CL, Wang T, Ou CQ. Comorbidity and its impact on 1590 patients with Covid-19 in China: A Nationwide Analysis. Eur Respir J 2020;55(5):2000547. 
23. Borges do Nascimento IJ, Cacic N, Abdulazeem HM, von Groote TC, Jayarajah U, Weerasekara I, Esfahani MA, Civile VT, Marusic A, Jeroncic A, Carvas Junior N. Novel coronavirus infection (COVID-19) in humans: a scoping review and meta-analysis. J Clin Med 2020;9(4):941.

24. Varatharaj A, Thomas N, Ellul MA, Davies NW, Pollak TA, Tenorio EL, Sultan M, Easton A, Breen G, Zandi M, Coles JP. Neurological and neuropsychiatric complications of COVID-19 in 153 patients: a UKwide surveillance study. Lancet Psychiatry 2020;Jun 25 (Published online ahead of print).

25. Li Y, Wang M, Zhou Y, Chang J, Xian Y, Mao L, Hong C, Chen S, Wang Y, Wang H, Li M. Acute cerebrovascular disease following COVID-19: a single center, retrospective, observational study. Stroke 2020; Jul 8 (Published online ahead of print).

26. Bianchetti A. Clinical presentation of COVID-19 in dementia patients. J Nutr Health Aging 2020;24(6):560-2.

27. Stojanovic A, Martorell L, Montalvo I, Ortega L, Monseny R, Vilella E, Labad J. Increased serum interleukin6 levels in early stages of psychosis: associations with at-risk mental states and the severity of psychotic symptoms. Psychoneuroendocrinology 2014;41:23-32.

28. Fonseca L, Diniz E, Mendonca G, Malinowski F, Mari J, Gadelha A. Schizophrenia and COVID-19: risks and recommendations. Brazil J Psychiatry 2020;42(3):236-8.

29. Huang KJ, Su IJ, Theron M, Wu YC, Lai SK, Liu CC, Lei HY. An interferon- $\gamma$-related cytokine storm in SARS patients. J Med Virol 2005;75(2):185-94.

30. Del Rey A, Besedovsky HO. Immune-neuro-endocrine reflexes, circuits, andnetworks: physiologic and evolutionary implications. Front Horm Res 2017;48:1-18.

31. Cheng SKW, Tsang JSK, Ku KH, Wong CW, Ng YK. Psychiatric complications in patients with severe acute respiratory syndrome (SARS) during the acute treatment phase: a series of 10 cases. Br J Psychiatry 2004; $184: 359-60$.

32. Lyons-Weiler J. Pathogenic Priming Likely Contributes to Serious and Critical Illness and Mortality in COVID-19 via Autoimmunity [published online ahead of print, 2020 Apr 9]. J Transl Autoimmun 2020;3:100051.

33. Panariello A, Bassetti R, Radice A, Rossotti R, Puoti M, Corradin M, Moreno M, Percudani M. Anti-NMDA receptor encephalitis in a psychiatric Covid-19 patient: A case report. Brain Behav Immun 2020;87:179-81.

34. Shanafelt T, Ripp J, Trockel M. Understanding and addressing sources of anxiety among health care professionals during the COVID-19 pandemic. JAMA 2020;323(21):2133-4.

35. Dantzer R, O'Connor JC, Freund GG, Johnson RW, Kelley KW. From inflammation to sickness and depression: when the immune system subjugates the brain. Nat Rev Neurosci 2008;9(1):46-56.

36. Ganguli R, Yang Z, Shurin G, Chengappa KR, Brar JS, Gubbi AV, Rabin BS. Serum interleukin-6 concentration in schizophrenia: elevation associated with duration of illness. Psychiatr Res 1994;51(1):1-10.

37. Miller AH, Haroon E, Raison CL, Felger JC. Cytokine targets in the brain: impact on neurotransmitters and neurocircuits. Depress Anxiety 2013;30:297-306.

38. Yang JJ, Wang N, Yang C, Shi JY, Yu HY, Hashimoto K. Serum interleukin-6 is a predictive biomarker for ketamine's antidepressant effect in treatment-resistant patients with major depression. Biol Psychiatry 2015;77(3):e19-20.

39. Jokela M, Virtanen M, Batty GD, Kivimäki M. Inflammation and Specific Symptoms of Depression. JAMA Psychiatry 2016;73(1):87-8.

40. Zhu J, Ji P, Pang J, Zhong Z, Li H, He C, Zhang J, Zhao C. Clinical characteristics of 3,062 COVID-19 patients: a meta-analysis. J Med Virol 2020;92:1902-14.

41. Baumeister, D., Ciufolini, S. \& Mondelli, V. Effects of psychotropic drugs on inflammation: consequence or mediator of therapeutic effects in psychiatric treatment?. Psychopharmacol 2016;233:1575-89.

42. Chen ML, Tsai TC, Lin YY, Tsai YM, Wang LK, Lee MC, Tsai FM. Antipsychotic drugs suppress the AKT/NF-kB pathway and regulate the differentiation of T-cell subsets. Immunol Lett 2011;140(1-2):81-91.

43. Oyesanmi O, Kunkel EJS, Monti DA, Field HL. Hematologic side effects of psychotropics. Psychosomatics 1999; 40:414-21.

44. Siskind D, Honer WG, Clark S, Correll CU, Hasan A, Howes O, Kane JM, Kelly DL, Laitman R, Lee J, MacCabe JH. Consensus statement on the use of clozapine during the COVID-19 pandemic. J Psychiatr Neurosci 2020;45(4):200061-.

45. Mascolo A, Berrino PM, Gareri P, Castagna A, Capuano A, Manzo C, Berrino L. Neuropsychiatric clinical manifestations in elderly patients treated with hydroxychloroquine: a review article. Inflammopharmacology 2018;26(5):1141-9.

46. Liverpool Drug Interactions Group. Covid-19 drug interactions. University of Liverpool; 2020.

47. Papola D, Ostuzzi G, Gastaldon C, Morgano GP, Dragioti E, Carvalho AF, Fusar-Poli P, Correll CU, Solmi M, Barbui C. Antipsychotic use and risk of life-threatening medical events: umbrella review of observational studies. Acta Psychiatr Scand 2019;140(3):227-43.

Acknowledgements - Nil;
Conflict of Interest - Nil;
Funding - Nil

